\title{
Soil and Subsurface Sediment Microzonation Using with Seismic Refraction Tomography for Site Assessment (Case Study: IKIA Airport, Iran)
}

\author{
Khalil Rezaei \\ Department of Geology, Faculty of Earth Sciences, Kharazmi University, Tehran, Iran \\ Email: khalil.rezaei@khu.ac.ir \\ Received 16 February 2016; accepted 18 March 2016; published 21 March 2016 \\ Copyright (C) 2016 by author and Scientific Research Publishing Inc. \\ This work is licensed under the Creative Commons Attribution International License (CC BY). \\ http://creativecommons.org/licenses/by/4.0/

(c) (i) Open Access

\section{Abstract}

The site effects relating to the amplification of ground motion under earthquake loading are strongly influenced by both the subsurface soil condition and the geologic structure. In this study, for site characterization at the Imam Khomeini International Airport (IKIA) area in south of Tehran, insitu seismic refraction tomography were carried out as a part of site investigations project, in addition geologic setting, borehole drilling, ground waters information and measurements. Based on seismic refraction studies, three layers are separable which with increasing in depth the $S$ and $P$ wave velocity is increased and this indicates increasing in compaction of soil and geologic materials. In the second and third separated layers, the zones with low and high seismic shear wave velocity is approximately equal, and northeast and southwest of the airport site has the low velocities, in addition to containing loose soils, highly weathered stones, and low depth to groundwater. In terms of Poisson's ratio, the most important and key installations of airport site are located in suitable positions. According to Iranian Seismic Code, most of the lands around the airport are in class $\mathbf{2}$ and 3. It seems that a fault or a discontinuity is passed from northwest to the southeast of the study area. This site, according to geological, subsurface geophysical, and geotechnical boreholes studies, is high risk-earthquake prone.

\section{Keywords}

Seismic Refraction Tomography, Microzonation, Soil, Sediment 


\section{Introduction}

Information such as faulting and fracturing, bedding plane direction, the presence of pore fluids, complex geological structure and detailed stratigraphy are commonly interpreted from 2D or 3D seismic data sets [1]-[6]. These geological structures are objects of geological discern in geophysical investigation that inform the "competence" or otherwise of the sub-surface. In the world of shallow geophysics, there are similarities between seismic reflection, seismic refraction, and ground-penetrating radar. In a seismic investigation, acoustic energy propagation is measured within a medium. The velocity of acoustic energy in the form of compressional and shear waves is related to the dynamic elastic module and density of a material [3] [7] [8].

The use of seismic surveys in foundation studies and groundwater exploration has traditionally relied on seismic refraction techniques using compressional waves which show increasing velocity with density [6] [7]. The earth is characterized by many layers, each with different physical properties. When sound waves travel through the earth encounter a change in the physical properties of the material in which they travel, they will either reflect back to the surface or penetrate deeper into the earth; where they may again be reflected at another interface. At a geological interface some seismic energy will react when it encounters a subsurface layer [8] [9]. This physical property is closely associated with the density of a layer. Acoustic energy is diffracted by fractured rock surfaces in much the same way that a visual image is distorted in a shattered mirror. Identifying diffracted energy patterns is one way in which geological structures such as faults and fractures can be identified and mapped [7] [9].

The field measurements can be carried out on the ground, in boreholes, on the seabed, or just below the sea surface. In each case, the refracted head wave travels parallel to the ground surface. Seismic wave velocities are calculated from the slope in a 'travel time versus distance' graph worked out from the registrations in geophones placed along the measured profile. The determination of the seismic velocities and the thickness of the various layers of is a complex process, and a great deal of practical experience is required of the operator before the results can be regarded as reliable [10].

The purpose of this paper is not to present a thorough explanation of exploration seismic methods, since this explanation can be found in any basic textbook on exploration geophysics [11]-[13]. It is important to know, however, that certain similarities exist between various seismic methods, and what the general limitations of the methods are. In all seismic methods, some source of seismic energy is used and some type of receiver is needed to detect seismic energy that has traveled through some volume of the earth.

In General, there are four various seismic methods for underground exploration including Seismic Cross-hole Tomography, Vertical Seismic Profiling, Shallow Seismic Reflection, and Seismic Refraction. Cross-hole seismic tomography offers means to investigate elastic properties of the rock mass between two or more boreholes. This technique has been developed and applied in the last 30 years in a number of settings worldwide [14]. Cross -hole seismic travel time tomography is based on the assumption that the energy travels from a source (lowered into a borehole) to a receiver (lowered into another neighboring borehole) along a well constrained ray path [15]. The technique is computationally intensive, and is costly because of the need for boreholes. It often gives a very detailed velocity model between the boreholes, and does not require any assumptions to be theoretically correct. This method has been used to study the interior of the earth from scales of thousands of kilometers to tens of meters [16] [17]. One of the more applications of this method is in economic geology and estimation of metal grades in deposits [18]-[20]. The vertical seismic profiling (VSP) technique is seldom used alone, but rather is used to provide better interpretation of seismic reflection data.VSP allows accurate determination of one-way travel time to various geologic units and analysis of attenuation and acoustic impedances which are needed for construction of synthetic seismograms. The synthetic seismograms are then used for comparison with seismic-reflection data to identify specific geologic formations and to refine depth estimates of those formations. References on VSP include [21]-[23]. The studies of [24] and [25] can be referenced as new application of VSP in underground evaluation. Shallow seismic reflection involves using a surface seismic source to create a seismic wave, which then travels into the subsurface. At interfaces that have an impedance contrast, (change in velocity and/or density) a portion of these waves is reflected back to the ground surface, and a portion is transmitted through the interface. These transmitted waves then reflect at the next impedance contrast and return to the ground surface. Geophones on the ground surface record these reflections. In shallow seismic reflection method the source and receiver intervals employed is $2.0-5.0 \mathrm{~m}$ [26]. seismic refraction is one of the most commonly used methods to determine bedrock depths, especially for depths of less than $30 \mathrm{~m}$. Seismic refraction method makes use of waves travelling along the ground surface and of waves in the underlying more compact layers 
where the velocities are higher (Figure 1) [13]. They return to the surface as refracted waves which are sometimes called head waves [27].

In this study, the seismic refraction method was used for addressing the Robat-Karim fault beneath the Imam Khomeini International Airport (IKIA) and its surrounding. The seismic refraction method has been used in various and numerous studies [28]-[31]. Such as this investigation, the seismic refraction technique has been used in several cases for evaluation, finding and detecting the faults and fracture zones in underground environments [32]-[34].

In IKIA site, seismic refraction studies were performed to determine the velocity of seismic waves in underground layer sand strength of geological formations at different depth. In addition, other main objectives of this study was included: accurate detection of surface and subsurface layers and geologic units, sedimentological study of the region in terms of grading, sorting, porosity and permeability, identify and separate zones of loose clay soils according to geological hazards, study of tectonic and associated complications such as faults, discontinuities, fractures and folding, and determine the depth of bed rock. All collected data in this study can be used to determine the different land-use positions in future, according to engineering fundamentals.
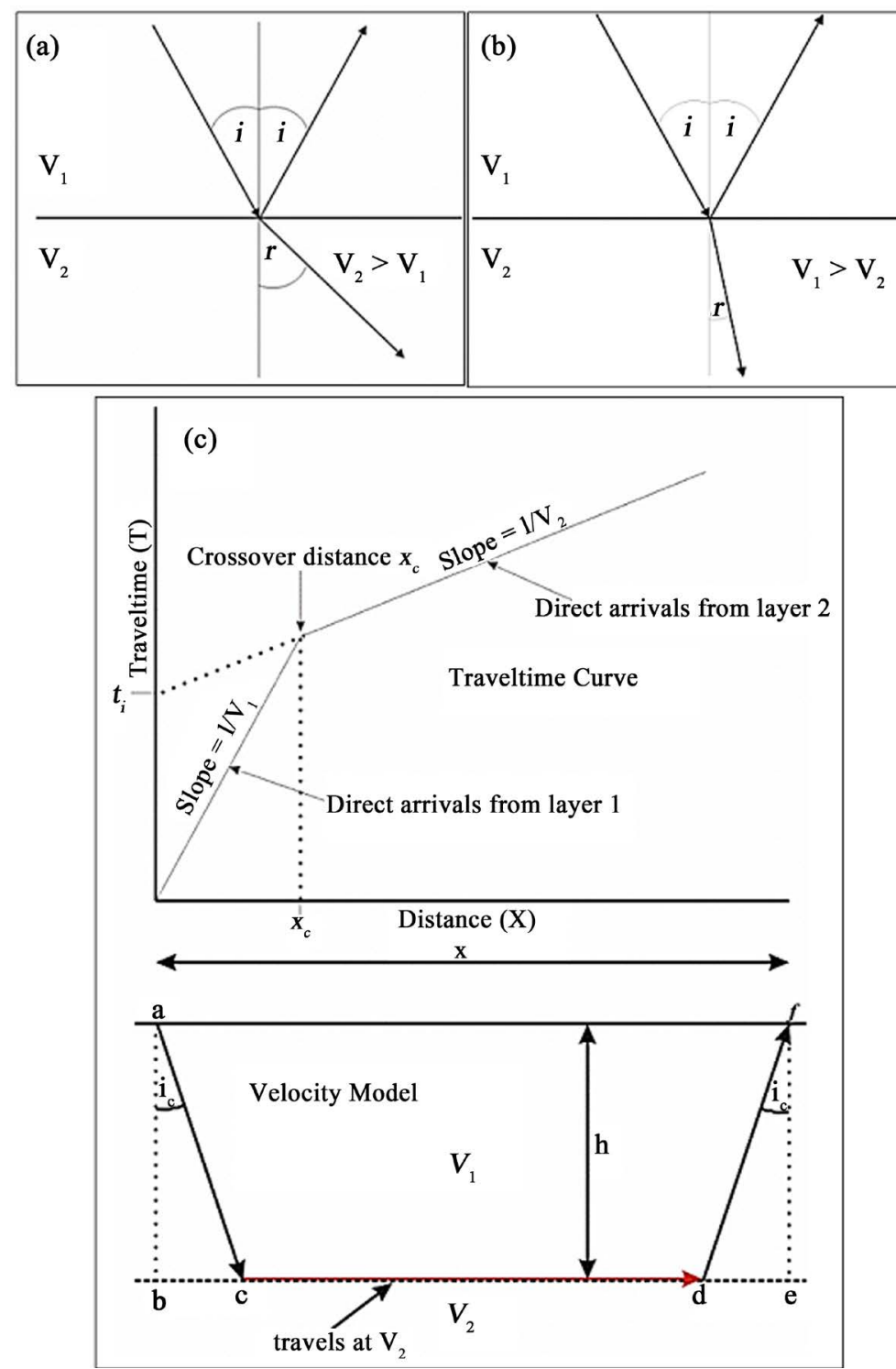

Figure 1. ((a) (b)) Seismic wave travels; showing simple refraction occurring at an interface; (c) Time-Distance graph for seismic refraction. 


\section{Materials and Methods}

\subsection{Main Concept of Seismic Refraction Method}

The seismic refraction technique is based on the refraction of seismic energy at the interfaces between subsurface/geological layers of different velocity. The seismic refraction method uses very similar equipment to seismic reflection, typically utilizing geophones in an array, and a seismic source (shot). When a seismic wave encounters an interface between two different rock types, some of the energy is reflected and the remainder continues on its way at a different angle, i.e., it is refracted [28] [35].

The law of reflection is very simple; the angle of reflection is equal to the angle of incidence. Refraction on the other hand is governed by Snell's law, which relates the angles of incidence and refraction to the seismic velocities in the two media as follows [28]:

$$
\frac{\sin i}{\sin r}=\frac{v_{1}}{v_{2}}
$$

If $v_{2}$ is greater than $v_{1}$, refraction will be towards the sini equals $v_{1} / v_{2}$, the parallel to the interface and some of its energy will return to the surface as a head wave that at the original angle of incidence. At greater angles of incidence there can be no refracted ray and all the energy is reflected. Simple refraction is showed in Figure 1(a), Figure 1(b). The cross-over distance for which the travel times of the direct and refracted waves are equal is shown in below equation [9]:

$$
X_{C}=2 h \sqrt{\left[\left(v_{2}+v_{1}\right) /\left(v_{2}-v_{1}\right)\right]}
$$

$X_{c}$ is always more than double the interface depth and is large if the depth is large or the difference in velocities is small. The cross over distance is the distance at which the first arrival times are direct signals (Miao et al., 2012). It marks the point when the refracted wave overtakes and arrives before the direct wave. It is related to the refractor depth, $h$, (Figure 1(c)) and the velocities of the overlying medium and the refractor $v_{1}$ and $v_{2}$ respectively. The term critical distance is used for the minimum distance at which refractions return to the surface [9]. When the velocity is higher in the underlying layer there is a particular angle of incidence known as the critical angle, $i_{c}$, for which the angle of refraction is $90^{\circ}$. This gives rise to a critically refracted ray that travels along the interface at the higher velocity $v_{2}$ [28].

In a seismic refraction survey, the data extracted consist of sets of times (usually first-arrival times) measured by geophones at various distances from the source positions [9] [36]. These times are plotted against distances (Figure 1(c)). The gradient of any line is equal to the reciprocal of a velocity, i.e. steep slopes correspond to slow velocities [9].

The total travel time along the refraction ray path, is "acdf" (where " $a$ " is the source of the wave). The refraction time $T_{R}$ is given by:

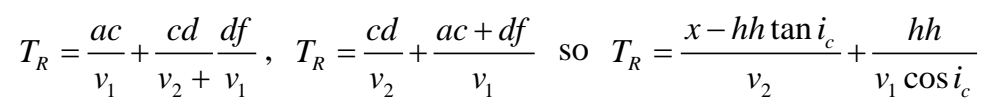

But $\sin i_{c}=v_{1} / v_{2}$ and $\cos i_{c}=\left(1-v_{1}^{2} / v_{2}^{2}\right)^{1 / 2}$.

The travel time may be expressed as:

$$
T_{R}=\frac{x \sin i_{c}}{v_{1}}+\frac{2 h \cos i_{c}}{v_{1}} \text { and Alternatively, } T_{R}=\frac{x}{v_{2}}+\frac{2 h\left(v_{2}^{2}-v_{1}^{2}\right)^{1 / 2}}{v_{1} v_{2}}
$$

The intercept time, $T_{i}$, is given as:

$$
T_{i_{c}}=\frac{2 h\left(v_{2}^{2}-v_{1}^{2}\right)^{1 / 2}}{v_{1} v_{2}}
$$

where $v_{1}$ and $v_{2}$ are the true velocities in the first and second media, respectively. The intercept time, $T_{i c}$ is defined as the time at which the back-extrapolated refracted arrival line cuts the time axis [9] [36]. Intercept times are conventionally obtained by drawing best-fit lines through the refracted arrival times but even a very good fit 
is no guarantee that the depth of the refractor does not change in the region near the shot point, from which no refractions are observed.

\subsection{Materials}

In this study, a seismic equipment-set consist of a hammer for striking the shot-point (wave source), a highspeed digital data recording systems called seismographs (ADEN Terraloc MK8 24 channel seismograph), a seismic imager software (Seistw program) and acoustic sensors called geophones (30 Geophone (P) 10 HZ, 25 Geophone (P) $30 \mathrm{HZ}$, and 30 Geophone (S) $10 \mathrm{HZ}$ ) were used.

\subsection{Data Acquisition}

In this study, the approximately 100 square kilometers of Imam Khomeini International Airport (IKIA) site were considered for seismic data collecting. The 24 seismic refraction profiles including 12 longitudinal wave profiles and 12 shear wave profiles were performed. For each data gathering in $\mathrm{P}$ profiles five shots and in $\mathrm{S}$ profiles six shots with shear wave sources and mutual reverse polarity are done. Figure 3 is presented the position of seismic refraction profiles.

In addition, data from field observations, condition of surface sediments, morphology of the area, slope and topography of formations in plain, the shallow excavated trench for subway, and spatially 6 boreholes data were used as guideline for better interpretation of seismic refraction survey.

\section{Site Description}

The study area was Imam Khomeini International Airport (IKIA) and its environs, between longitudes 505,000 to 518,000 and latitudes 391,400 to 392,300 . This site which has about $100 \mathrm{~km}^{2}$ area is located about 30 kilometers (19 mi) southwest of the city of Tehran, near the localities of Robat-Karim and Eslamshahr. Based on hydrologic divisions, this area is the lowest parts of the Tehran basin and Robat-Karim, Shour rivers reach to this area in the end of their path. Morphologically, the study area composed of flat alluvial plain and low-lying hilly and the general topography slop is north to the south. Average slope angle of hills is approximately 20 to 40 degrees and for flat alluvial plain is generally between 5 to 10 degrees. Field observations show that the surface sediments in the northern part of the area are mostly fine grain and loose sediments and in the south of area coarse grain and dense conglomerate layers can be observed. In this area, sediments have the poor and very poor sorting which fall in range from gravel to clay. Due to Robat-Karim fault, study area has the relatively high seismicity and risk potential (Figure 2, Figure 3).

\section{Results and Discussion}

Seismic refraction data obtained on all 12 profiles were plotted in a time-distance graph which one of them shown below in Figure 4 for example, the compressional velocity; $v p$ and shear velocity; $v s$ of the various zones measured on whole profiles are recorded as shown in the Table 1 . In all profiles, results show that the IKIA site is generally composed of three layers with different $\mathrm{P}$ and $\mathrm{S}$ wave velocities and consequently thickness and Poisson's ratios (Table 2).

The seismic P wave velocity maps for IKIA site are showed in Figure 5. The first layer in the central area of Terminal 2 and West of site has the high is over $900 \mathrm{~m} / \mathrm{s}$ while in the north, south, and east is reduced to about 300 to $400 \mathrm{~m} / \mathrm{s}$. Low velocity shows weakness and lack of soil stability in north, south and east Airport site. Also in second layer, the northeast and southwest of site are shown the low velocities, and center and northwest of the site are shown the high velocities for compressional (P) wave. The second layer has a higher velocity values than first layer. It seems that most chosen positions for band and second terminal did not have a problem. The third layer shows the same trend as the second layer to the $\mathrm{P}$ wave. Based on the recorded seismic $\mathrm{P}$ waves for second layer, a number of active terminal bonds have not suitable condition and are constructed on weakness and loose lands.

The seismic S wave velocity maps for IKIA site are showed in Figure 6. Recorded Waves in the first layer shows the high velocity (more than $400 \mathrm{~m} / \mathrm{s}$ ) in central area of terminal 2 and west of site, and very low values (less than $200 \mathrm{~m} / \mathrm{s}$ ) is recorded for north and south of the site. Areas with low velocities are composed of loose and weak compaction which construction planes in these areas will be required to comply the standard design 
principles. In the second and third separated layers, the zones with low and high seismic shear (S) wave velocity is approximately equal, and northeast and southwest of the airport site has the low velocities, in addition to containing loose soils, highly weathered stones, and low depth to groundwater. Therefore, the engineering condition of these areas should be more considered during the construction operations. Based on average seismic $\mathrm{S}$ wave velocity map, the north and south lands of the airport have the velocity faster than $420 \mathrm{~m} / \mathrm{s}$, and is composed of loose and inappropriate formations (earth type 3 and 4). In addition, the center and northwest lands of the airport site is very strength and according to Iranian Seismic Code [37] are first class.

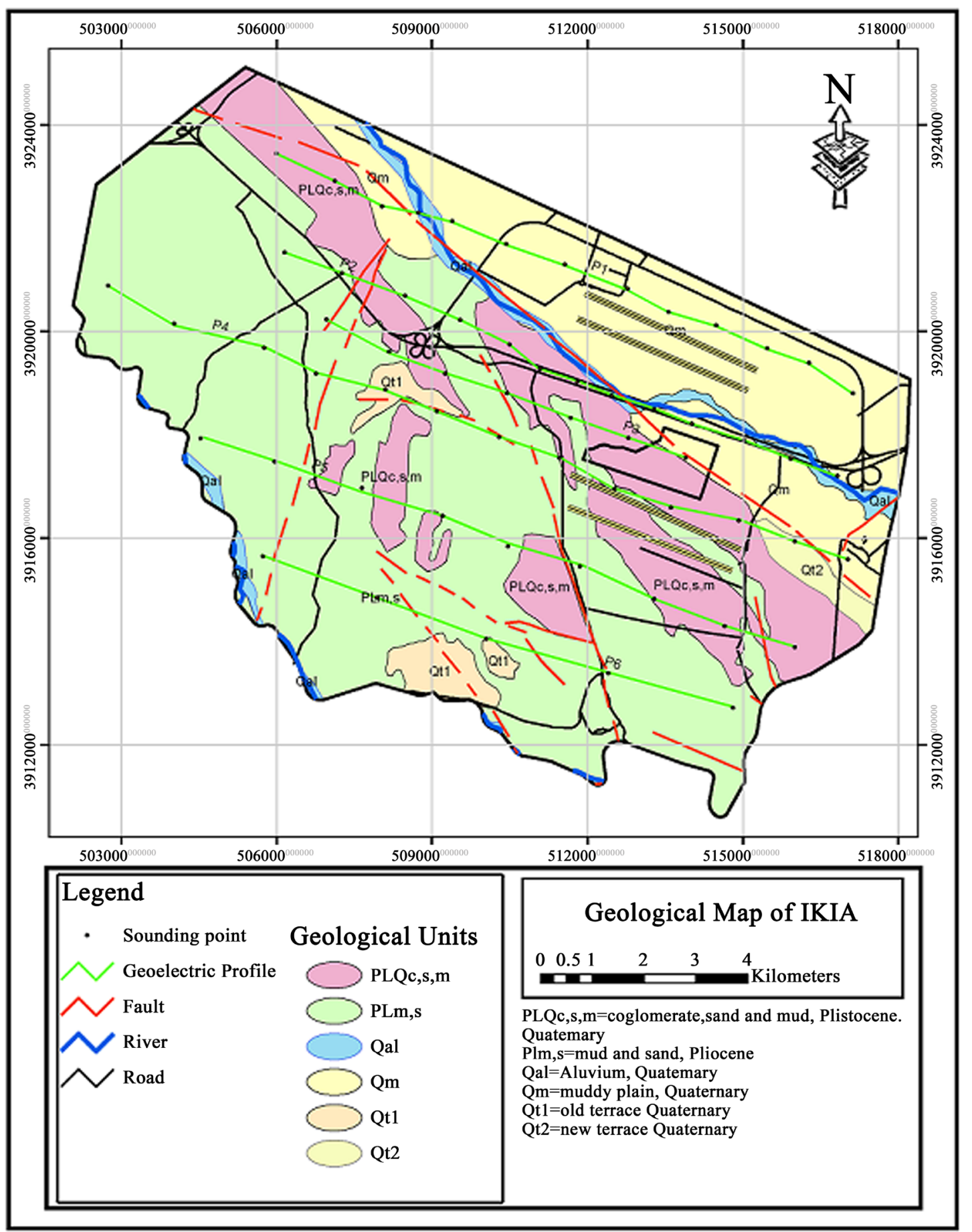

(a) 


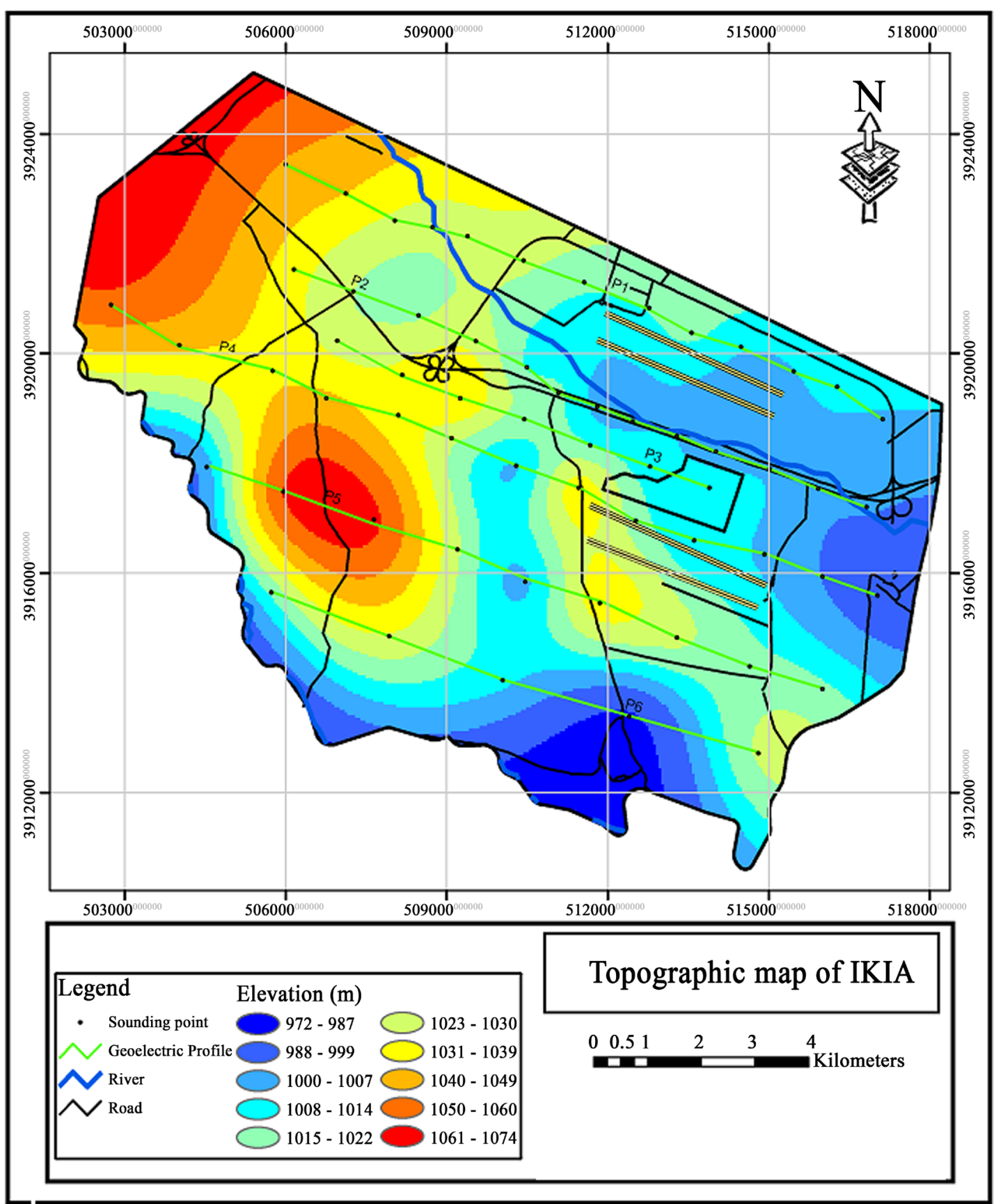

(b)

Figure 2. Geological map (a) and topographic map (b) of study area.

In this study, the thickness of each layer is calculated and the beginning and the end of them are measured and the iso-depth of layers is mapped (Figure 7). In first layer, the maximum thickness (up to $11 \mathrm{~m}$ ) can be addressed in north and south of area and minimum thickness (1 to $3 \mathrm{~m}$ ) is available in west and east of this site. For second layer, maximum (17 to $19 \mathrm{~m}$ ) and minimum (7 to $8 \mathrm{~m}$ ) thickness can be observed in south and northwest, and west and east of area, respectively. At the northeast and southwest of the area, seismic bedrock is in the deepest state (about 22 to 24 meters), and at the northwest of the airport site is located about 13 meters. Of course, the seismic bedrock is not equal to geology bedrock, it seems that high compaction of coarse-grained alluvial sediments has been cause the making of seismic bedrock. 


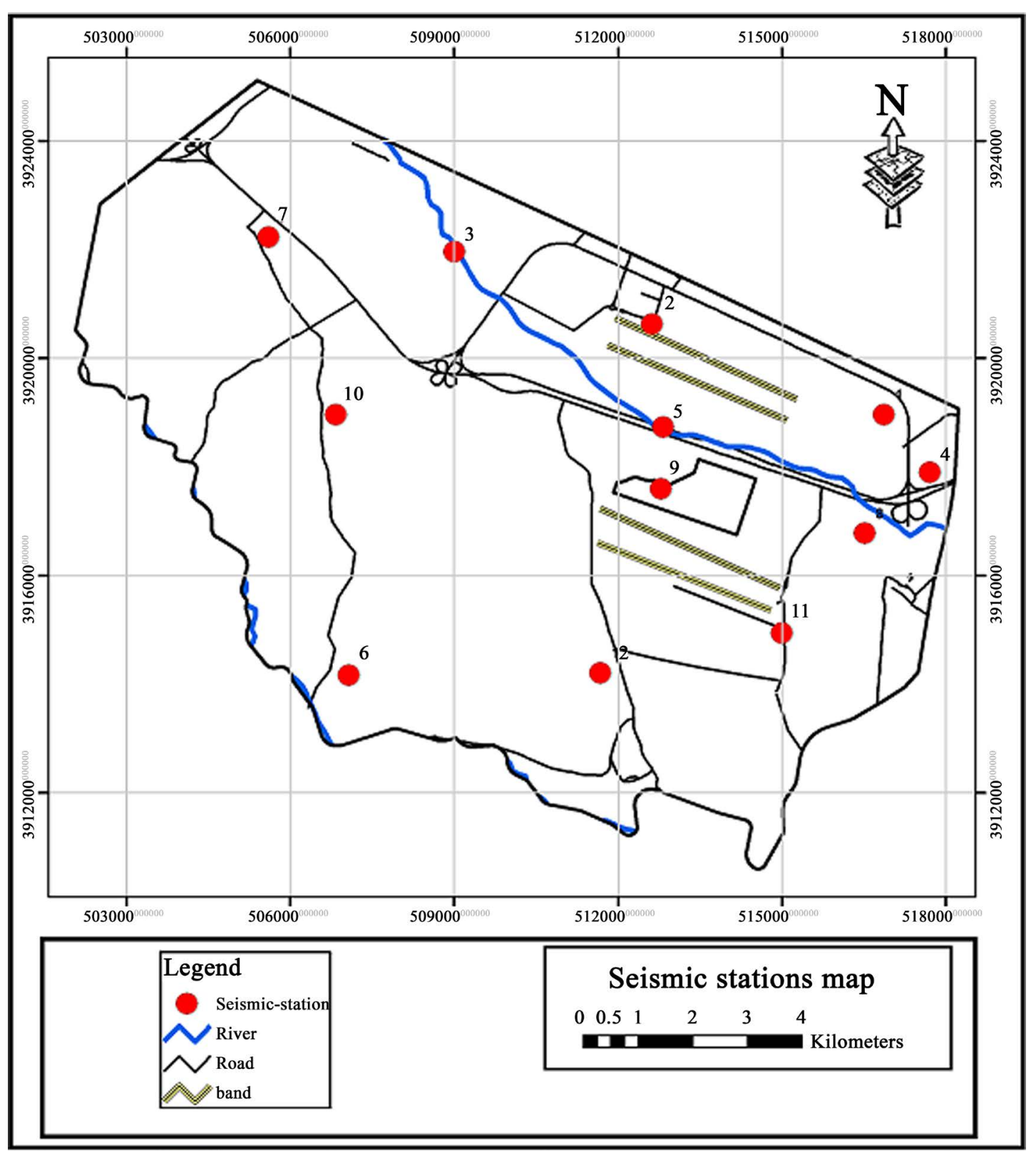

Figure 3. Position of seismic refraction profiles.

The maps of Poisson's ratio for the three layers are showed in Figure 8. Poisson's ratio for the first layer is in rang 0.28 to 0.4 , and this value is gradually increases from east to west of site. The east of airport site shows the lowest and southwest and north of active terminal bands Airport lowest has the highest Poisson's values. According to Poisson's ratio, the first layer is composed of sand with medium density [38] so; most parts of this site are suitable for future constructions. Poisson's ratio of the second layer has changed in range 0.22 to 0.37 (loose sands) and just central parts and terminals 1, 2 are showed higher values and lowest Poisson's ratio was recorded for east and west of site. In third layer, the Poisson's ratio was between 0.18 to 0.43 which show the vast range of particle size from sand and gravel, silty sand and dens sand [38].

\section{Conclusions}

The geology conditions and risk assessment in Imam Khomeini International Airport (IKIA) based on seismic refraction survey can be expressed as follows: 
- Based on seismic refraction studies, three layers are separable which with increasing in depth the $\mathrm{S}$ and $\mathrm{P}$ wave velocity is added and this indicates increasing in compaction of geology formations.

- In the second and third separated layers, the zones with low and high seismic shear (S) wave velocity is approximately equal, and northeast and southwest of the airport site has the low velocities, in addition to containing loose soils, highly weathered stones, and low depth to groundwater. Therefore, the engineering condition of these areas should be more considered during the construction operations.

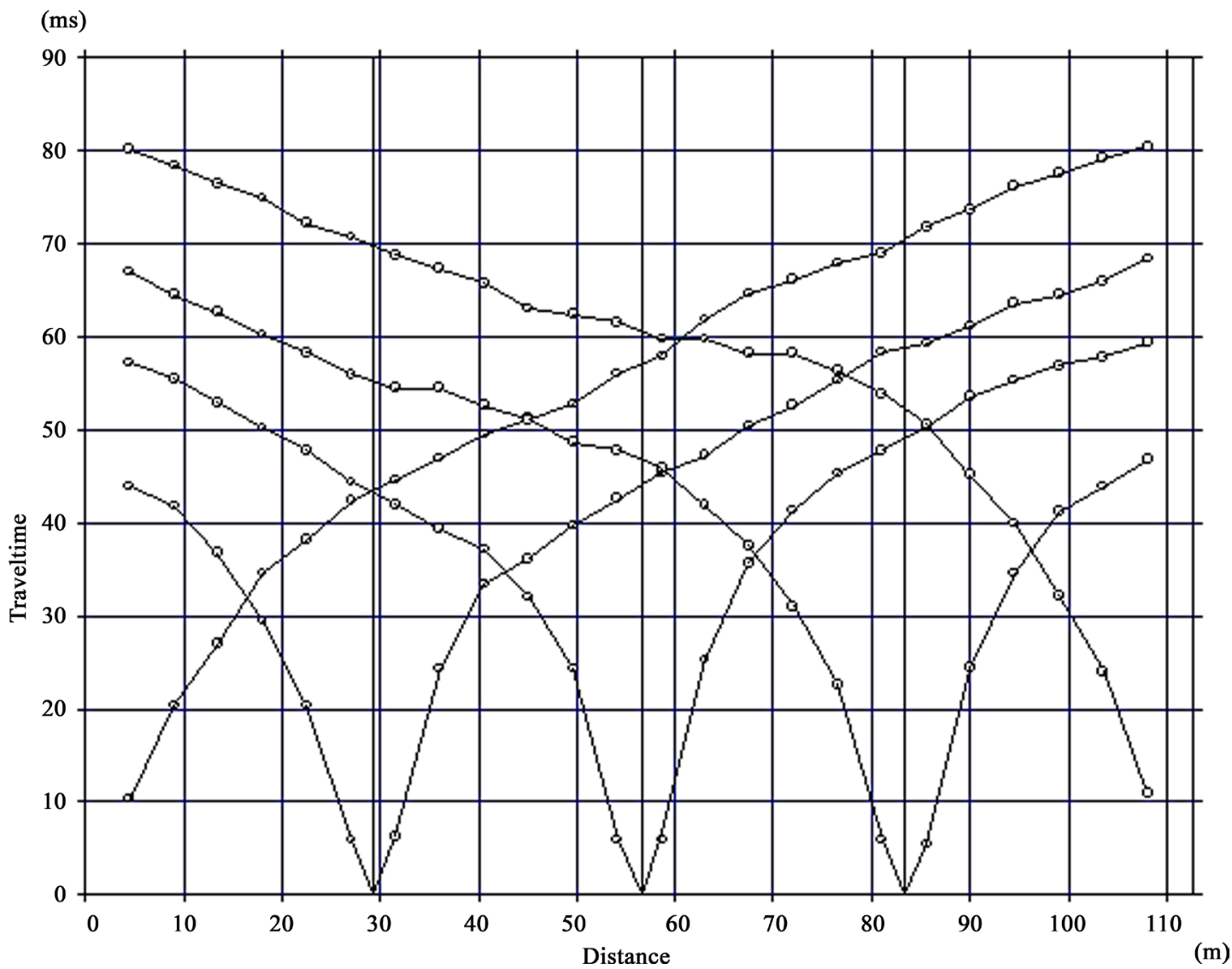

Figure 4. Time-Distance graph of P wave for profile 3 (for example).

Table 1. Values of P and S wave velocity for all layers.

\begin{tabular}{ccccccccccc}
\hline \multirow{2}{*}{$\begin{array}{c}\text { Profile } \\
\text { No. }\end{array}$} & \multirow{2}{*}{$\mathrm{X}(\mathrm{m})$} & $\mathrm{Y}(\mathrm{m})$ & \multicolumn{2}{c}{ First layer } & \multicolumn{2}{c}{ Second layer } & \multicolumn{2}{c}{ Third layer } & \multirow{2}{*}{$\begin{array}{c}v_{s} \\
\text { (Ave. to } 30 \mathrm{~m})\end{array}$} \\
\cline { 2 - 7 } 1 & 516,864 & $3,918,967$ & 650 & 300 & 950 & 500 & 1150 & 630 & 424 \\
2 & 512,626 & $3,920,627$ & 550 & 260 & 750 & 400 & 900 & 490 & 370 \\
3 & 509,004 & $3,921,954$ & 600 & 270 & 1650 & 940 & 2600 & 1520 & 705 \\
4 & 517,711 & $3,917,899$ & 550 & 250 & 950 & 550 & 1200 & 700 & 466 \\
5 & 512,826 & $3,918,739$ & 800 & 360 & 1500 & 680 & 1750 & 800 & 696 \\
6 & 509,528 & $3,920,174$ & 500 & 235 & 800 & 460 & 1050 & 620 & 390 \\
7 & 505,599 & $3,922,227$ & 850 & 390 & 1350 & 780 & 1550 & 910 & 765 \\
8 & 516,513 & $3,916,781$ & 550 & 260 & 1150 & 590 & 1600 & 820 & 443 \\
9 & 512,791 & $3,917,596$ & 950 & 460 & 1400 & 750 & 1650 & 940 & 706 \\
10 & 506,829 & $3,918,967$ & 800 & 350 & 1100 & 630 & 1300 & 780 & 573 \\
11 & 515,002 & $3,914,942$ & 750 & 360 & 1150 & 660 & 1400 & 820 & 643 \\
12 & 511,675 & $3,914,209$ & 500 & 250 & 1450 & 670 & 2250 & 830 & 476
\end{tabular}


Table 2. Values of Poisson's ratio and thickness for all layers.

\begin{tabular}{ccccccccc}
\hline \multirow{2}{*}{$\begin{array}{c}\text { Profile } \\
\text { No. }\end{array}$} & \multirow{2}{*}{$\mathrm{X}(\mathrm{m})$} & $\mathrm{Y}(\mathrm{m})$ & \multicolumn{2}{c}{ First layer } & \multicolumn{2}{c}{ Second layer } & \multicolumn{2}{c}{ Third layer } \\
\cline { 5 - 9 } & & $\mathrm{Z}(\mathrm{m})$ & Poisson' ratio & $\mathrm{Z}(\mathrm{m})$ & Poisson' ratio & $\mathrm{Z}(\mathrm{m})$ & Poisson' ratio \\
\hline 1 & 516,864 & $3,918,967$ & -10.5 & 0.36 & -11.5 & 0.31 & -22 & 0.29 \\
2 & 512,626 & $3,920,627$ & -7 & 0.36 & -15.5 & 0.3 & -22.5 & 0.29 \\
3 & 509,004 & $3,921,954$ & -6.5 & 0.37 & -7.5 & 0.26 & -14 & 0.24 \\
4 & 517,711 & $3,917,899$ & -6.5 & 0.3 & -12.5 & 0.25 & -19 & 0.35 \\
5 & 512,826 & $3,918,739$ & -2 & 0.37 & -11.5 & 0.37 & -13.5 & 0.23 \\
6 & 509,528 & $3,920,174$ & -8.5 & 0.36 & -11 & 0.25 & -19.5 & 0.24 \\
7 & 505,599 & $3,922,227$ & -2.5 & 0.37 & -14 & 0.25 & -16.5 & 0.32 \\
8 & 516,513 & $3,916,781$ & -9.5 & 0.36 & -13 & 0.32 & -22.5 & 0.26 \\
9 & 512,791 & $3,917,596$ & -6.5 & 0.35 & -12.5 & 0.3 & -19 & 0.22 \\
10 & 506,829 & $3,918,967$ & -5.5 & 0.38 & -17 & 0.26 & -22.5 & 0.22 \\
11 & 515,002 & $3,914,942$ & -3.5 & 0.35 & -15.5 & 0.25 & -19 & 0.24 \\
12 & 511,675 & $3,914,209$ & -8.5 & 0.33 & -11 & 0.36 & -19.5 & 0.42 \\
\hline
\end{tabular}

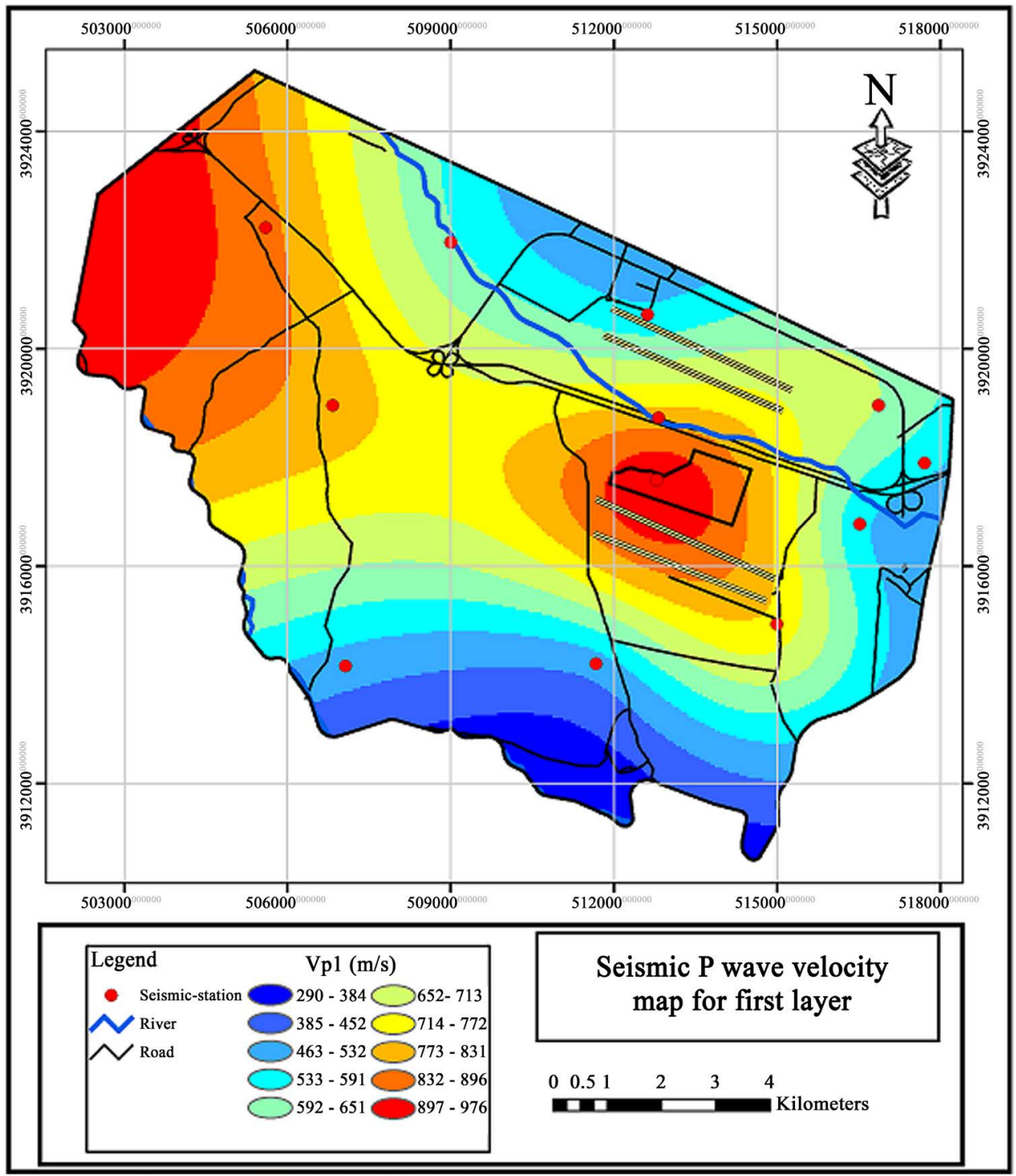

(a) 


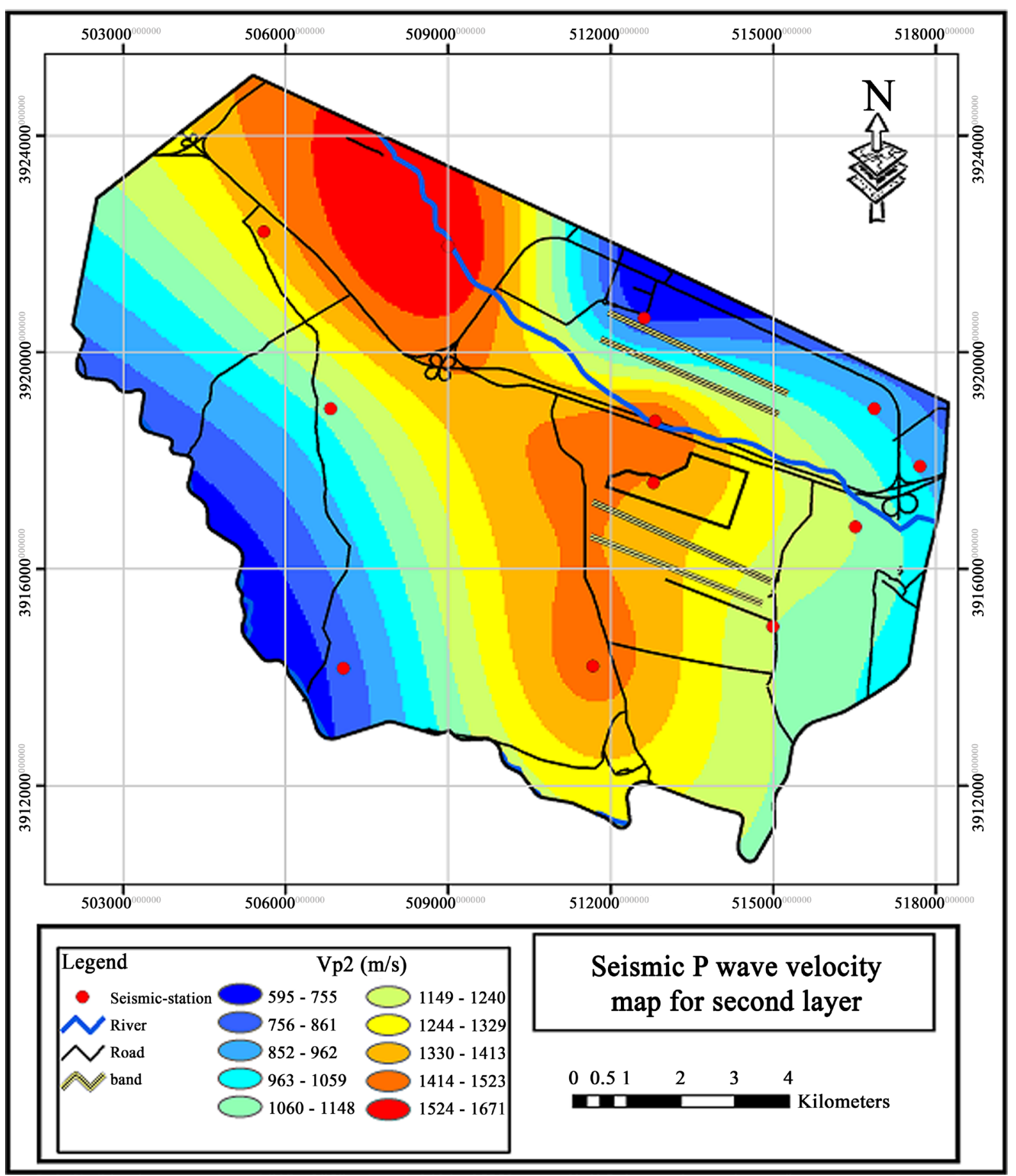

(b) 


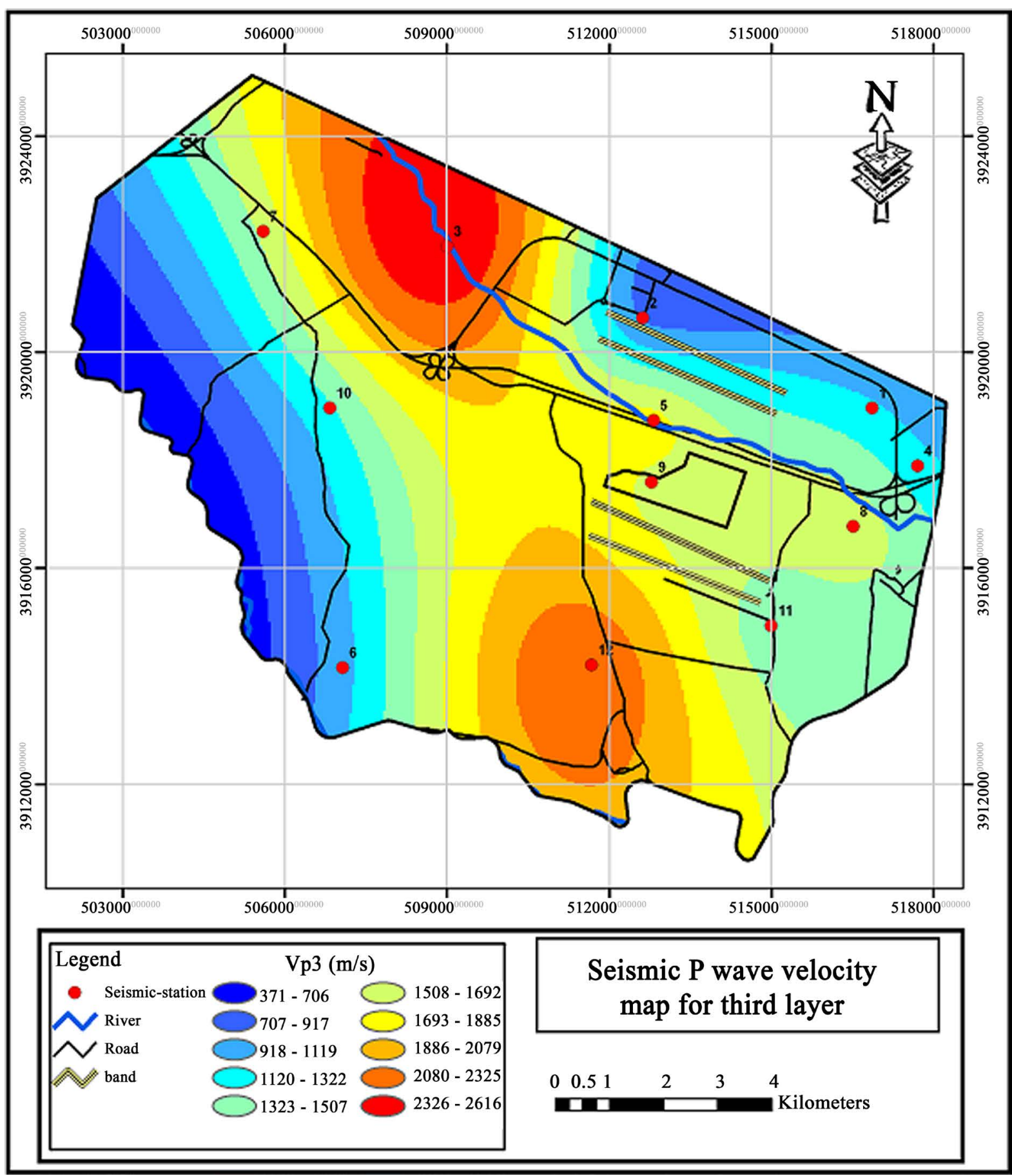

(c)

Figure 5. Seismic P wave velocity map of (a) First, (b) Second, and (c) Third layers. 


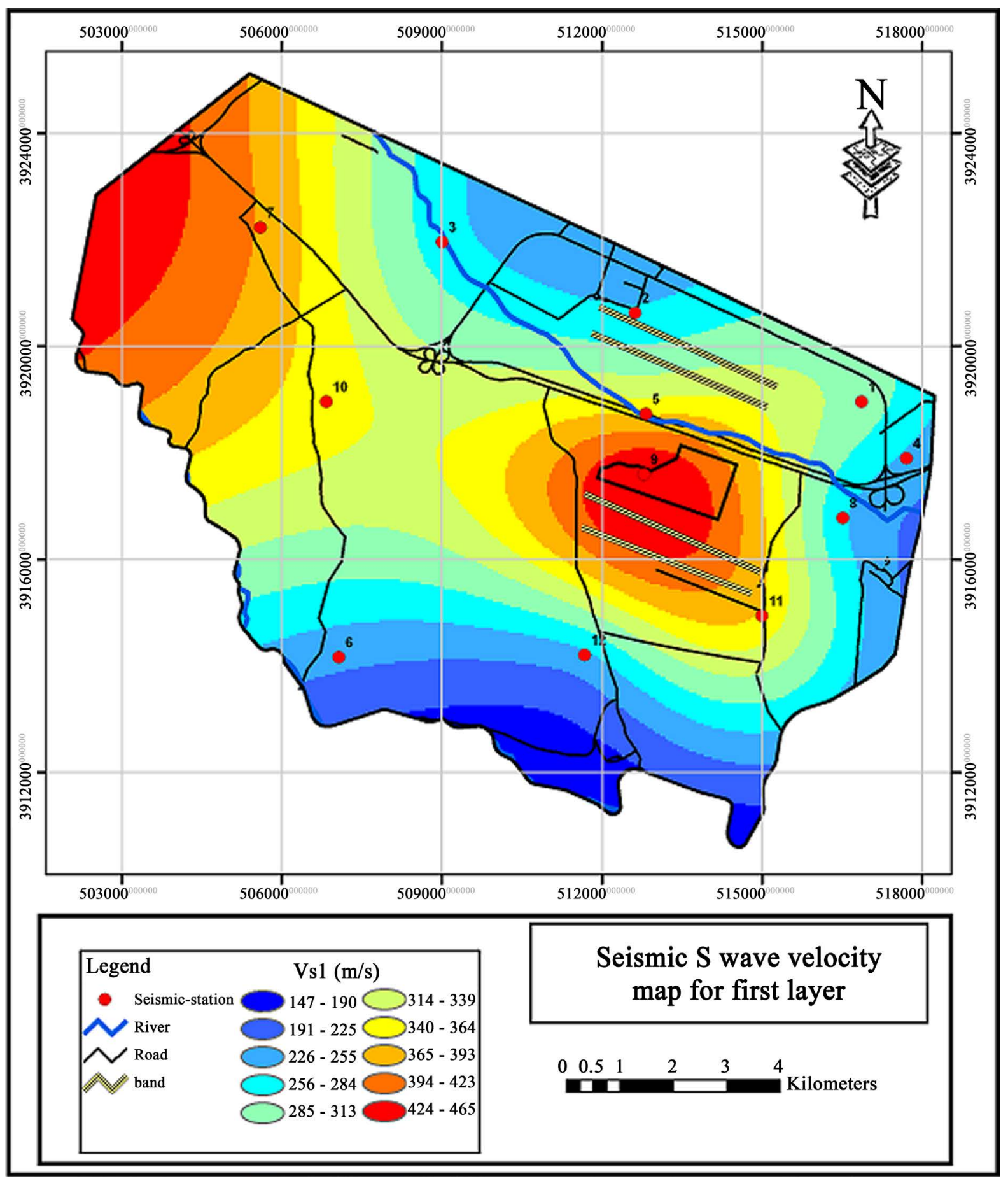

(a) 


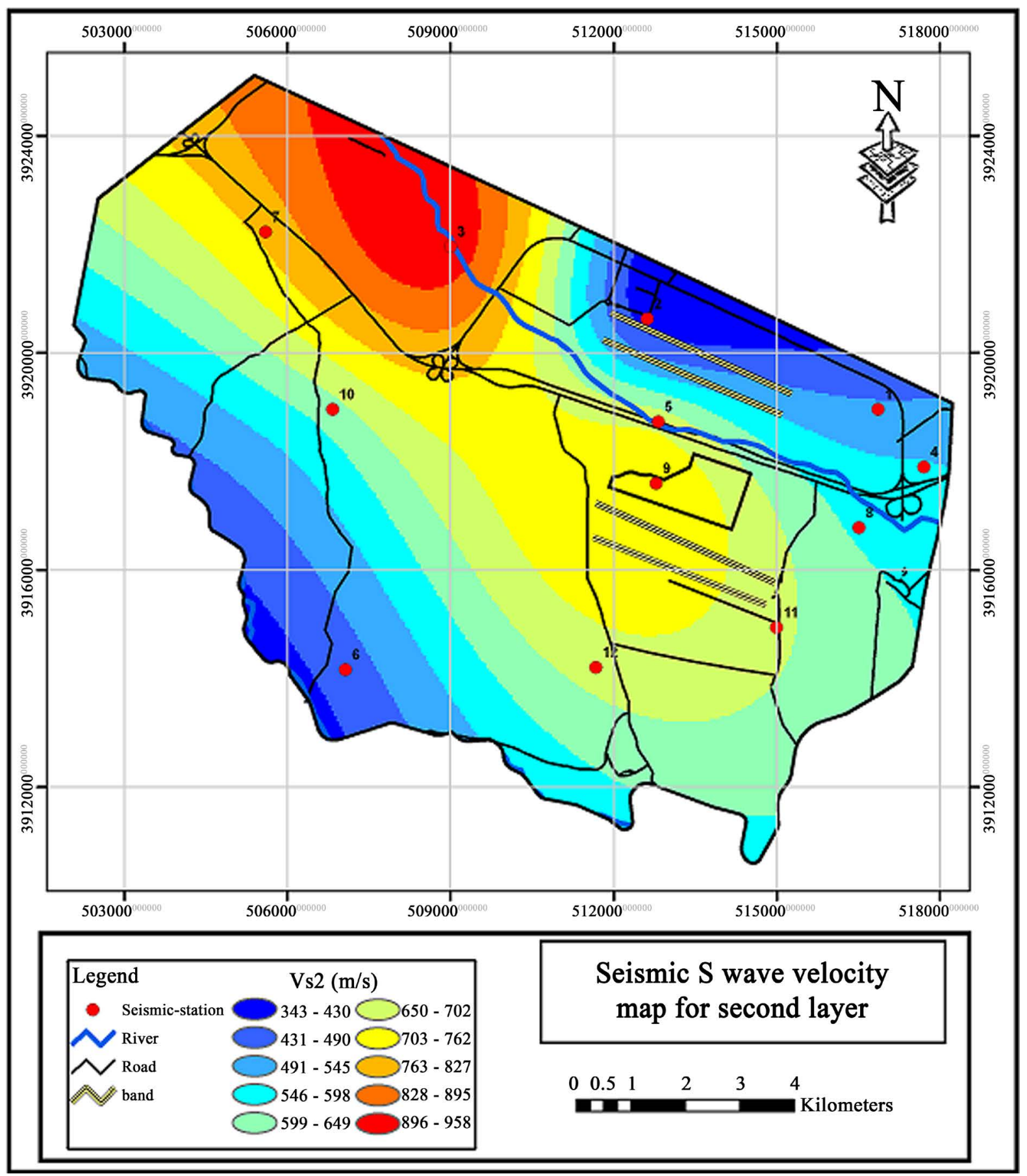

(b) 


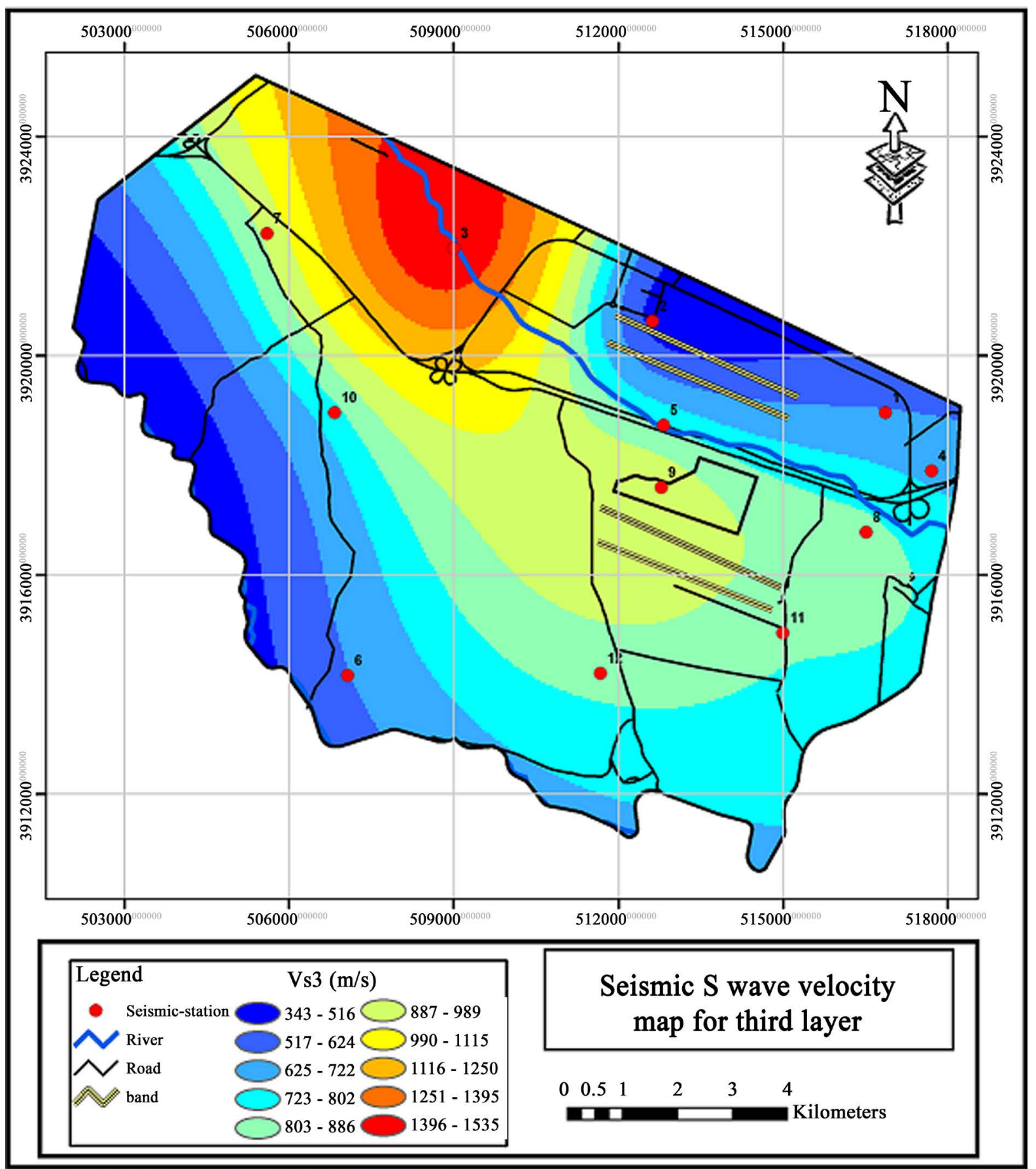

(c) 


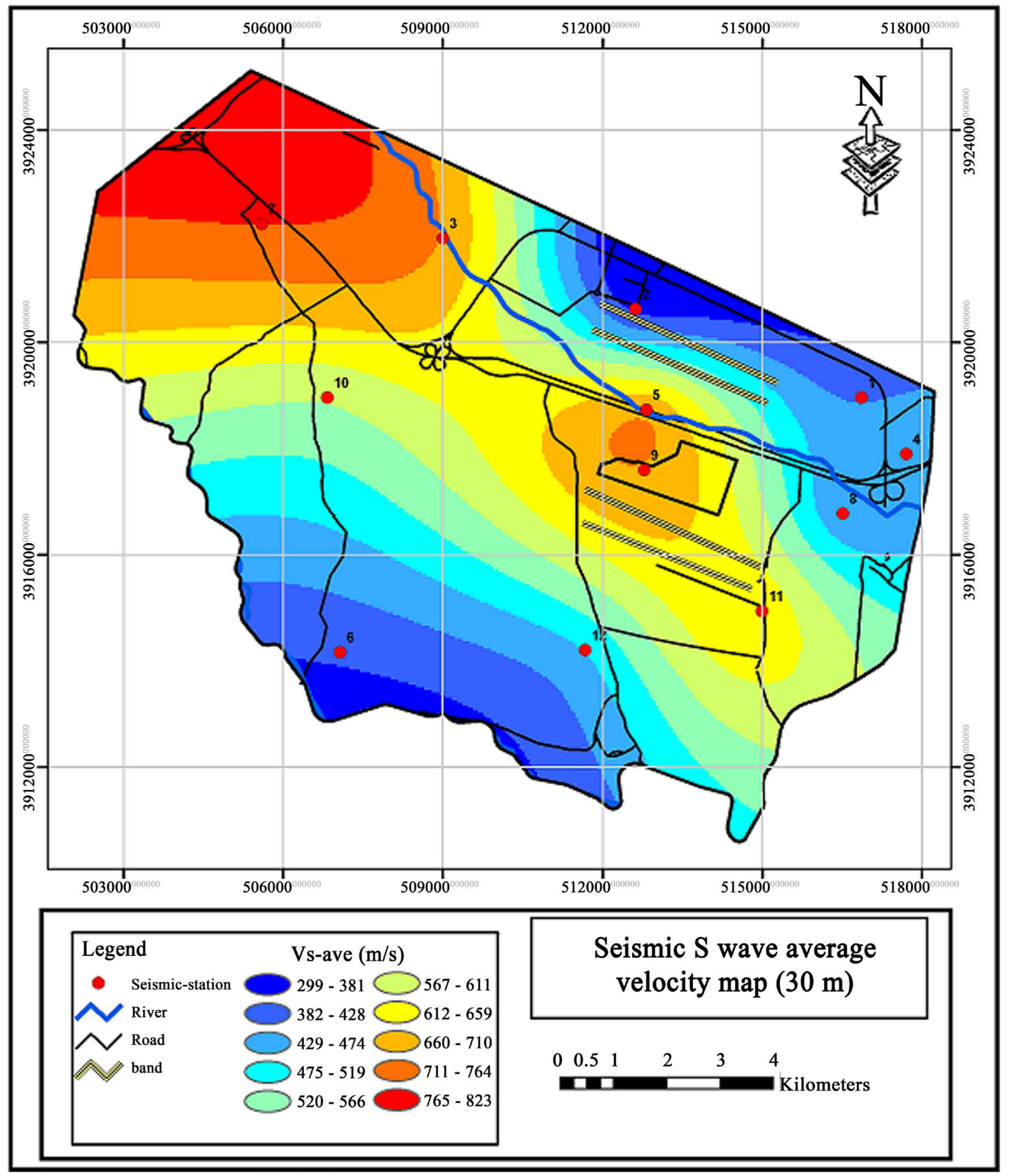

(d)

Figure 6. Seismic S wave velocity map of (a) First, (b) Second, (c) Third layers, and (d) Average velocity to depth $30 \mathrm{~m}$. 


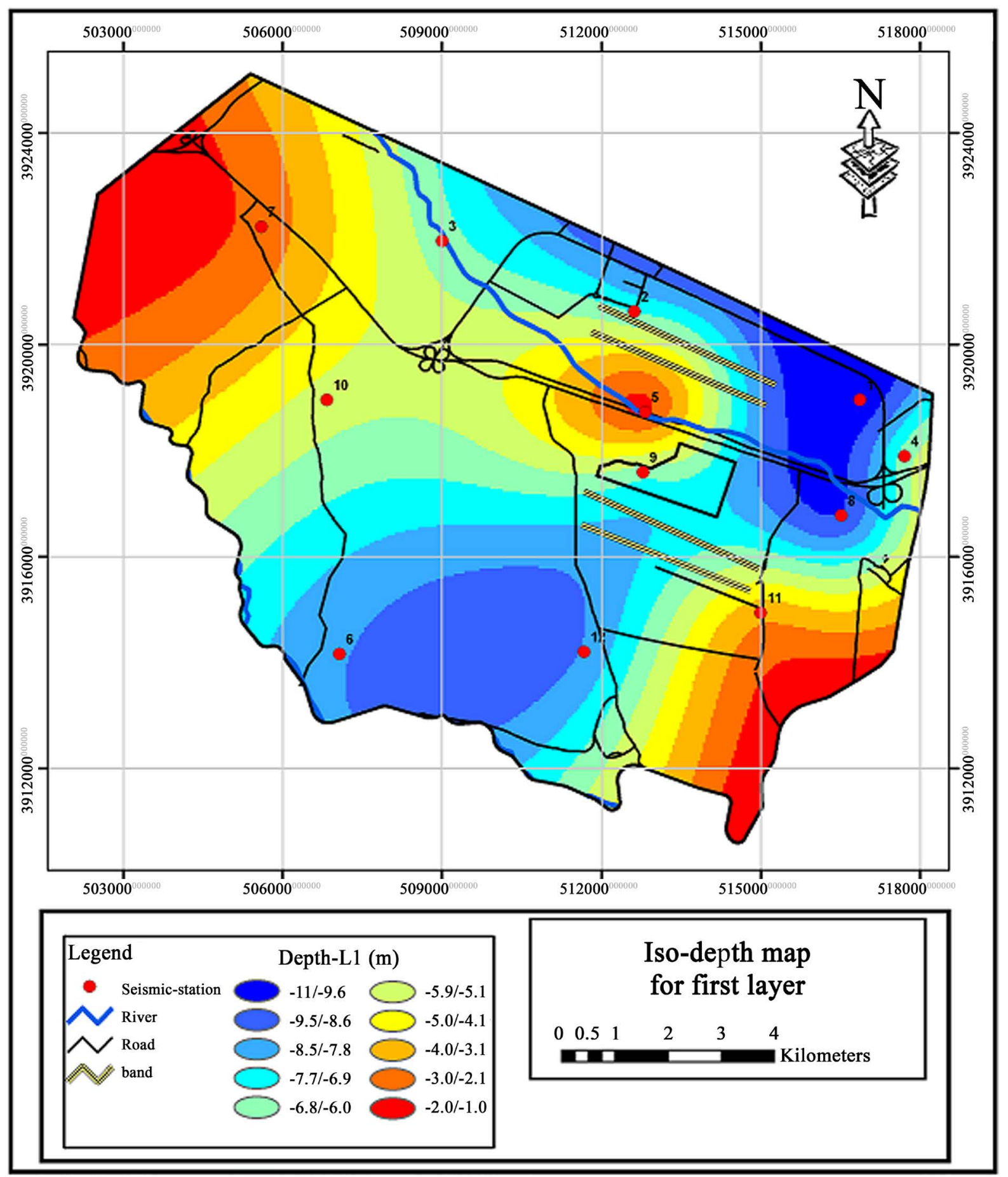

(a) 


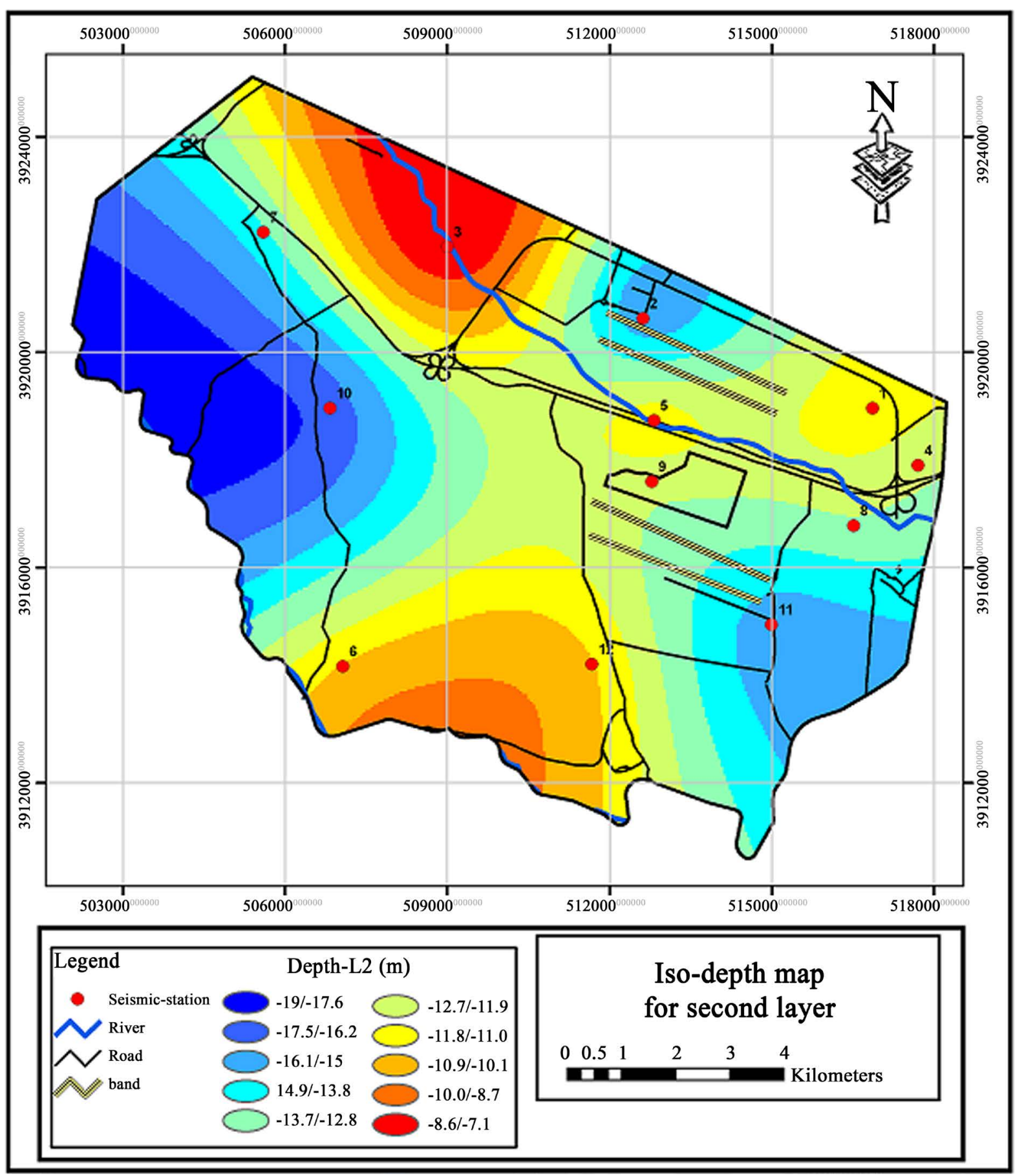

(b) 


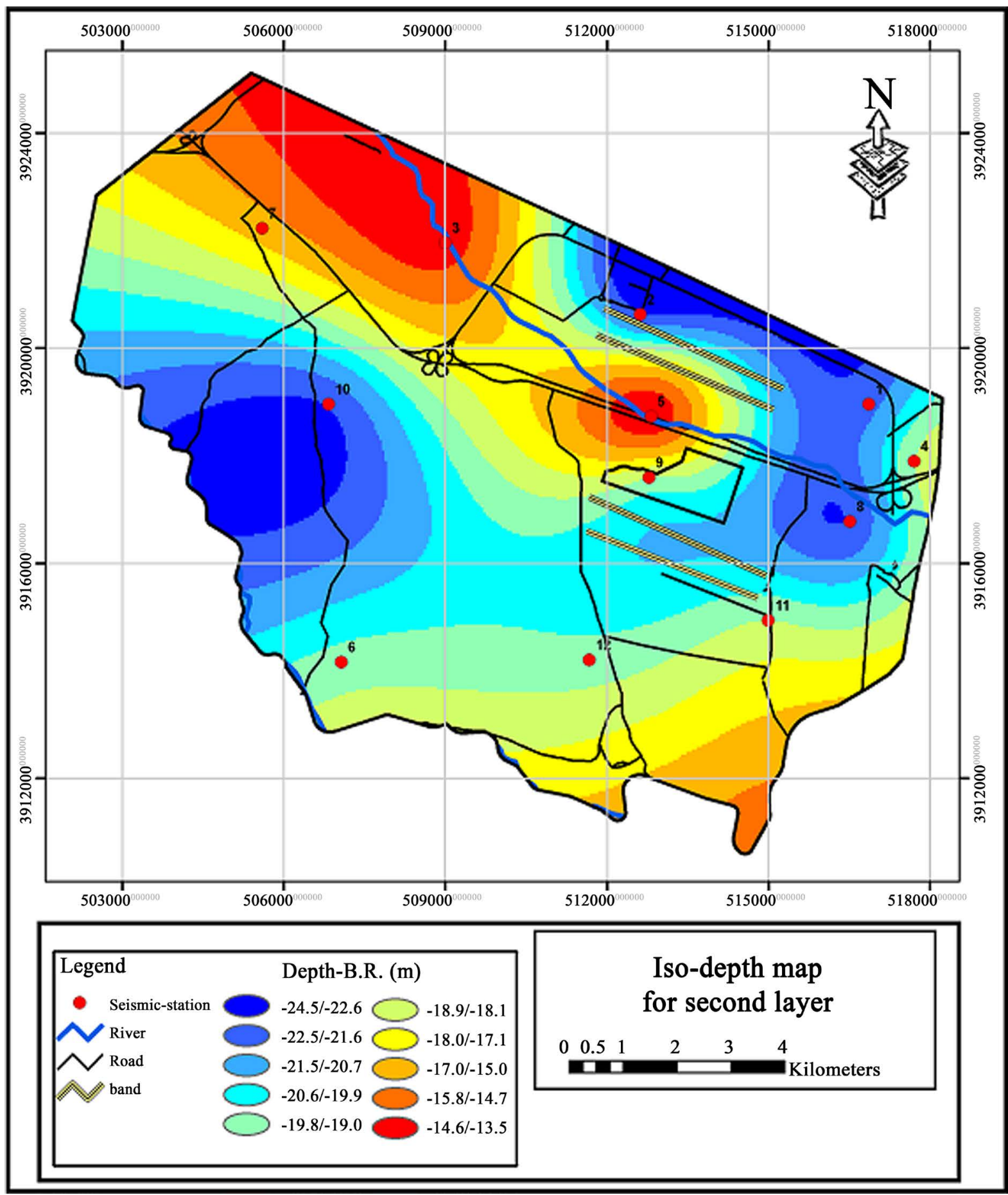

(c)

Figure 7. Iso-depth map for (a) First, (b) Second, and (c) Third (Bedrock) layers. 


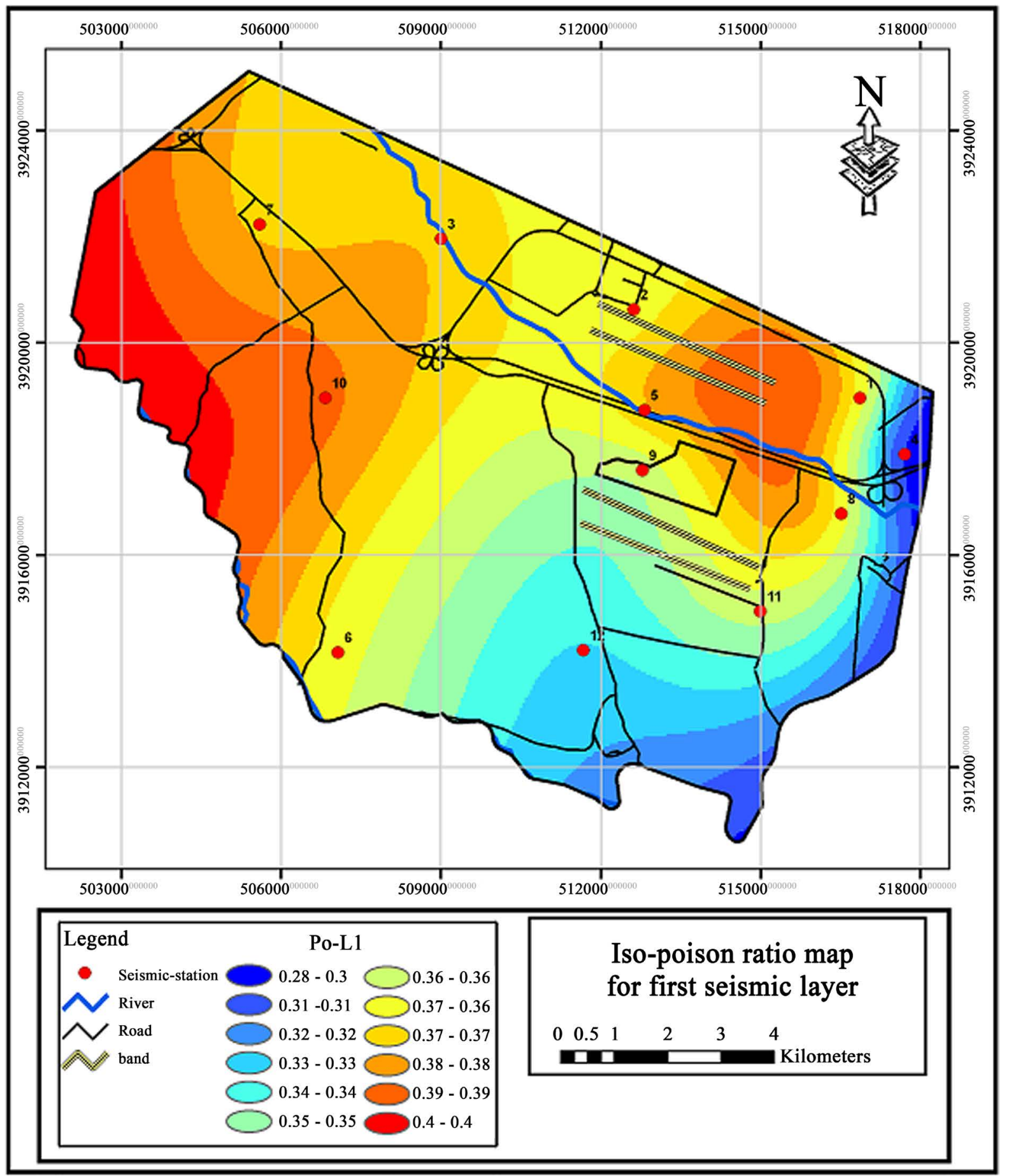

(a) 


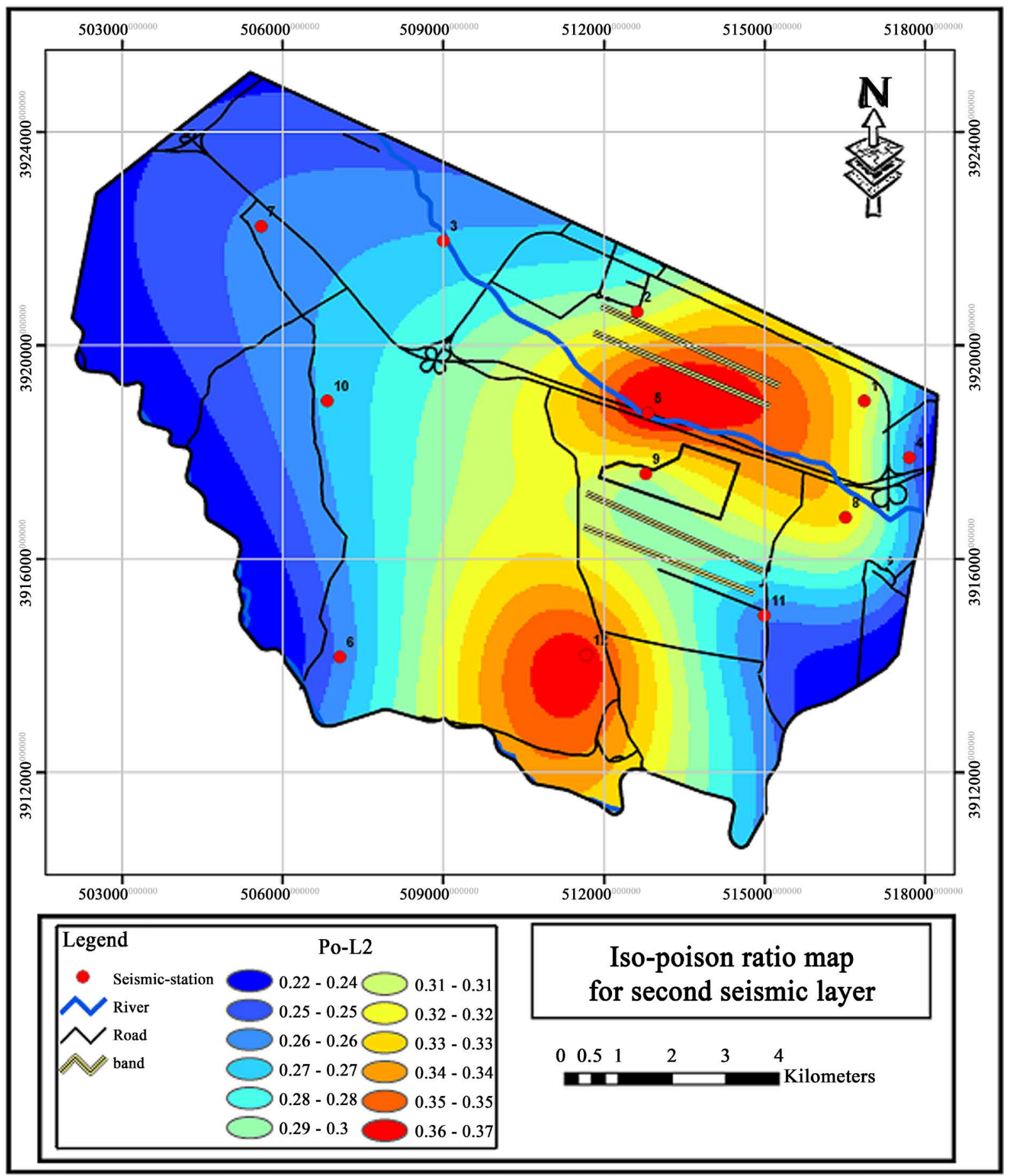

(b) 


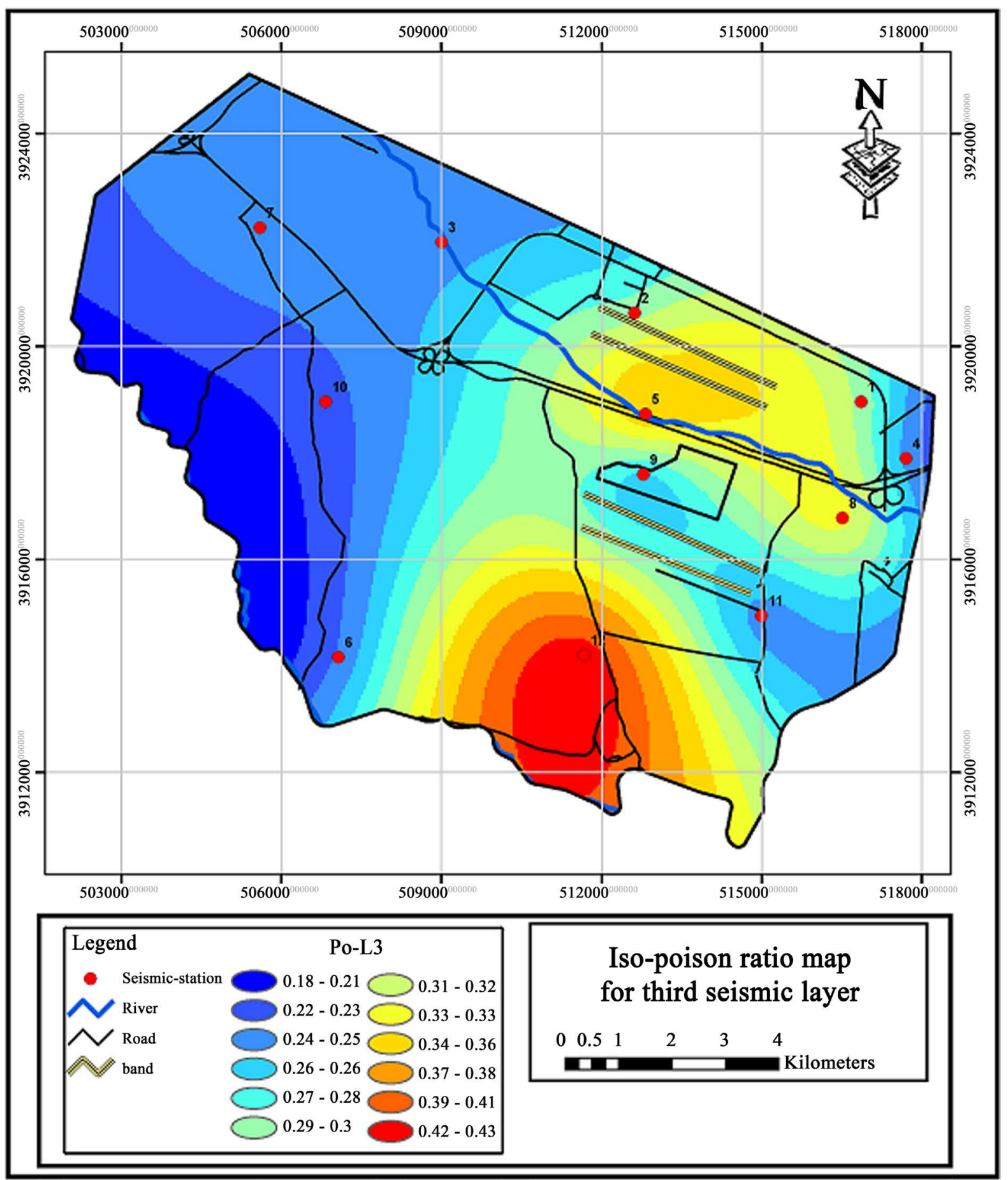

(c)

Figure 8. Iso-Poisson’ ratio map for (a) First, (b) Second, and (c) Third (Bedrock) layers. 
- Based on average seismic $S$ wave velocity map, the north and south lands of the airport have the velocity faster than $420 \mathrm{~m} / \mathrm{s}$, and is composed of loose and inappropriate formations (earth type 3 and 4 ). In addition, the center and northwest lands of the airport site are very strength and according to Iranian Seismic Code (Standard 2800) are first class.

- In terms of Poisson's ratio, the most important and key installations of airport site are located in suitable positions.

- At the northeast and southwest of the area, seismic bedrock is in the deepest state (about 22 to 24 meters), and at the northwest of the airport site is located about 13 meters. Of course, the seismic bedrock is not equal to geology bedrock, it seems that high compaction of coarse-grained alluvial sediments has been causing the making of seismic bedrock.

- According to Iranian Seismic Code [37], most of the lands around the airport are in class 2 and 3 and the future construction in this region will be required to comply with the standard design principles.

- It seems that a fault or a discontinuity is passed from northwest to the southeast of the study area and is caused the change in this part of the airport land range.

- In general, according to geological, subsurface geophysical, and geotechnical boreholes studies, this site in addition to soluble minerals has the high thickness of fine grain sediments with low to moderate compaction, Thus, this region is high risk-prone due to earthquake.

\section{References}

[1] Al-Heety, A.J.R. and Shanshal, Z.M. (2016) Integration of Seismic Refraction Tomography and Electrical Resistivity Tomography in Engineering Geophysics for Soil Characterization. Arabian Journal of Geosciences, 9, 73. http://dx.doi.org/10.1007/s12517-015-2116-9

[2] Ansal, A., Kurtulus, A. and Tonuk, G. (2010) Seismic Microzonation and Earthquake Damage Scenarios for Urban Areas. Soil Dynamics and Earthquake Engineering, 30, 1319-1328. http://dx.doi.org/10.1016/j.soildyn.2010.06.004

[3] Cordsen, A., Galbraith, M. and Peirce, J. (2000) Planning Land 3-D Seismic Surveys. Society of Exploration Geophysicists, 204 p. http://dx.doi.org/10.1190/1.9781560801801

[4] Grasso, S. and Maugeri, M. (2014) Seismic Microzonation Studies for the City of Ragusa (Italy). Soil Dynamics and Earthquake Engineering, 56, 86-97. http://dx.doi.org/10.1016/j.soildyn.2013.10.004

[5] James, N., Sitharam, T.G., Padmanabhan, G. and Pillai, C.S. (2014) Seismic Microzonation of a Nuclear Power Plant Site with Detailed Geotechnical, Geophysical and Site Effect Studies. Natural Hazards, 71, 419-462. http://dx.doi.org/10.1007/s11069-013-0919-0

[6] Vermeer, G.J.O. and Beasley, C.J. (2002) 3-D Seismic Survey Design. Society of Exploration Geophysicists, 205 p. http://dx.doi.org/10.1190/1.9781560801757

[7] Beck, A.E. (1993) Physical Principles of Exploration Methods. 2nd Edition, Wuerz Publishing Ltd., Canada, 292 p.

[8] Moore, J.E. (2002) Field Hydrogeology. 2nd Edition, CRC Press, Boca Raton, 195 p. http://dx.doi.org/10.1201/9781420032253

[9] Milsom, J. (2003) Field Geophysics. 3rd Edition, John Wiley \& Sons, New York, 244 p.

[10] Palmstrom, A. (1996) Application of Seismic Refraction Survey in Assessment of Jointing. Conference on Recent Advances in Tunnelling Technology, New Delhi, 18-20 March 1996, 1-8.

[11] Dobrin, M.B. (1976) Introduction to Geophysical Prospecting. McGraw-Hill Book Co., New York, 630 p.

[12] Sheriff, R.E. (1978) A First Course in Geophysical Exploration and Interpretation. International Human Resources Development Corporation, Boston, 313 p.

[13] Telford, W.M., Geldart, L.P., Sheriff, R.E. and Keys, D.A. (1990) Applied Geophysics. 2nd Edition, Cambridge University Press, Cambridge, 770 p. http://dx.doi.org/10.1017/CBO9781139167932

[14] Gustavsson, M., Israelson, H., Ivansson, S., Moren, P. and Pihl, J. (1984) An Experiment with the Seismic Crosshole Method in an Iron Mine. The Leading Edge, 3, 143-145. http://dx.doi.org/10.1190/1.1439029

[15] Perozzi, L., Gloaguen, E., Rondenay, S. and McDowell, G. (2012) Using Stochastic Crosshole Seismic Velocity Tomography and Bayesian Simulation to Estimate Ni Grades: Case Study from Voisey’s Bay, Canada. Journal of Applied Geophysics, 78, 85-93. http://dx.doi.org/10.1016/j.jappgeo.2011.06.036

[16] Clayton, R.W. and Stolt, R.H. (1981) A Born-WKBJ Inversion Method for Acoustic Reflection Data. Geophysics, 46, 1559-1567. http://dx.doi.org/10.1190/1.1441162

[17] Humphreys, G., Clayton, R.W. and Hager, B.H. (1984) A Tomographic Image of Mantle Structure beneath Southern 
California. Geophysical Research Letters, 11, 625-627. http://dx.doi.org/10.1029/GL011i007p00625

[18] Enescu, N., McDowell, G.M., Cosma, C. and Bell, C. (2002) Crosshole Seismic Investigations at Voisey’s Bay, Canada. SEG Technical Program Expanded Abstracts, 21, 1472-1475.

[19] Wong, J. (2000) Crosshole Seismic Imaging for Sulfide Ore-Body Delineation near Sudbury, Ontario, Canada. Geophysics, 65, 1900-1907. http://dx.doi.org/10.1190/1.1444874

[20] Xu, K. and Greenhalgh, S. (2010) Ore-Body Imaging by Crosswell Seismic Waveform Inversion: A Case Study from Kambalda, Western Australia. Journal of Applied Geophysics, 70, 38-45. http://dx.doi.org/10.1016/j.jappgeo.2009.11.001

[21] Balch, A.H. and Lee, M.W. (1984) Vertical Seismic Profiling: Techniques, Applications, and Case Histories. International Human Resources Development Corporation, Boston, 488 p.

[22] Galperin, E.I. (1974) Vertical Seismic Profiling. Society of Exploration Geophysicists Publication, 270 p.

[23] Hardage, B.A. (1985) Vertical Seismic Profiling, Part A: Principles. Geophysical Press, 509 p.

[24] Al Dulaijan, K., Owusu, J.C. and Webe D.C. (2012) Azimuthal Anisotropy Analysis of Walkaround Vertical Seismic Profiling Vertical Seismic Profiling: A Case Study from Saudi Arabia. Geophysical Prospecting, 60, 1082-1094. http://dx.doi.org/10.1111/j.1365-2478.2012.01107.x

[25] Miao, X., Moon, W.M., Milkereit, B. and Mwenifumbo, C.J. (1994) Three Component Vertical Seismic Profiling (VSP) Experiment in the Sudbury Basin. Geophysical Research Letters, 21, 939-942. http://dx.doi.org/10.1029/93GL02246

[26] Schmelzbach, C., Green, A.G. and Horstmeyer, H. (2005) Ultra-Shallow Seismic Reflection Imaging in a Region Characterized by High Source-Generated Noise. Near Surface Geophysics, 3, 33-46. http://dx.doi.org/10.3997/1873-0604.2004027

[27] Sjogren, B. (1984) Shallow Refraction Seismic. Chapman and Hall, London, 268 p. http://dx.doi.org/10.1007/978-94-009-5546-2

[28] Dawood, A.M.A, Akiti, T.T. and Glover, E.T. (2012) Seismic Refraction Investigation at a Radioactive Waste Disposal Site. Geosciences, 2, 7-13.

[29] Imhof, A., Luis Sanchez, M., Calvo, C. and Martin, A. (2011) Application of Seismic Refraction Tomography for Tunnel Design in Santa Clara Mountain, San Juan, Argentina. Earth Sciences Research Journal, 15, 81-88.

[30] Nisa, A., Rosli, S., Saidin, M.M. and Nordiana, M.M. (2012) Applying Seismic Refraction Method in Depicting Geological Contact at Bukit Bunuh, Lenggong, Perak, Malaysia. Proceedings of 2012 International Conference on Geological and Environmental Sciences, 36, 59.

[31] Williams, R.A., Stephenson, W.J., Odum, J.K. and Worley, D.M. (2005) P- and S-Wave Seismic Reflection and Refraction Measurements at CCOC. In: Asten, M.W. and Boore, D.M., Eds., Blind Comparisons of Shear-Wave Velocities at Closely Spaced Sites in San Jose, California, U.S. Geological Survey, Open-File Report 2005-1169. http://pubs.usgs.gov/of/2005/1169/

[32] Detrick, J.R.S. and Purdy, G.M. (1980) The Crustal Structure of the Kane Fracture Zone from Seismic Refraction Studies. Journal of Geophysical Research: Solid Earth, 85, 3759-3777. http://dx.doi.org/10.1029/JB085iB07p03759

[33] Eberhart-Phillips, D., Stanley, W.D. and Lutter, W.J. (1995) Surface Seismic and Electrical Methods to Detect Fluids Related to Faulting. Journal of Geophysical Research: Solid Earth, 100, 12919-12936. http://dx.doi.org/10.1029/94JB03256

[34] Wu, J. and Hole, J.A. (2011) Refraction of Fault-Zone Guided Seismic Waves. Bulletin of the Seismological Society of America, 101, 1674. http://dx.doi.org/10.1785/0120100024

[35] Gadallah, M.R. and Fisher, R.L. (2004) Applied Seismology. PennWell Books, 473 p.

[36] Kearey, P., Brooks, M. and Hill, I. (2009) An Introduction to Geophysical Exploration. 3rd Edition, Wiley, New York, $272 \mathrm{p}$.

[37] (2005) Iranian Code of Practice for Seismic Resistance Design of Buildings: Standard No. 2800. 3rd Edition, Building and Housing Research Center. (In Persian)

[38] Braja, M.D. (2008) Advanced Soil Mechanics. 3rd Edition, Routledge Publication, 567 p. 